\title{
Cultural Distance and the Export of Film and TV Works: Verification Based on China and B\&R Countries
}

\author{
Yanfeng Lei ${ }^{1, *}$, Jianyu Chi ${ }^{1}$, Mingkai Huang ${ }^{1}$ \\ ${ }^{1}$ School of Economics and Management, Communication University of China, Beijing, 100024, China \\ *Corresponding author. Email: 15712940851@163.com
}

\begin{abstract}
With the opportunity of "the Belt and Road" (B\&R) Initiative in recent years, Chinese film and television works have made phased progress in "going global". But there are still trade barriers caused by cultural differences such as "cultural discount" in the process of film and television industry internationalization. Based on Hofstede's cultural dimension theory as an analytical framework, this paper selects the data of China's export of film and television works from 54 B\&R countries from 2010 to 2018 as samples to empirically analyze the impact of cultural distance on the export of Chinese film and television works. And we process the endogeneity of the model by means of instrumental variable method. The findings are as follows: first, the cultural distance between China and B\&R countries has a significant hindering effect on the export of Chinese film and television works; second, the sub-dimension regression results of cultural distance further show that the three dimensions of power distance, masculinity/femininity and uncertainty avoidance have a negative impact on the export of Chinese film and television works.
\end{abstract}

Keywords: Cultural distance, film and television works export, "the Belt and Road" initiative

\section{INTRODUCTION}

In recent years, China has paid great attention to the development and internationalization of film and television industry. Supporting policies related to the production and dissemination of film and television works are frequently issued. However, the international competitiveness of China's film and television industry is still weak. In 2019, China's imported films earned about $\$ 3.347$ billion at the box office, while the total box office of Chinese films in North America was only \$20.48 million. It can be seen that China's film industry has a large trade deficit in import and export.

Of course, China has never stopped striving to gain the initiative and voice in foreign trade. In 2013, China put forward "the Belt and Road" Initiative, which is a cooperative initiative featuring diversity, openness and inclusiveness. Involving more than 100 countries in Asia, Africa, the Middle East and Europe, the initiative has served as a bridge for cultural exchanges between China and many countries along the Route across multiple regions and cultures. Taking advantage of this opportunity, China's foreign film and television industry has achieved initial results, and many films and television works with Chinese cultural characteristics are well known to the audiences of B\&R countries. From 2013 to 2018, China's total export of film and television products to $B \& R$ countries increased by 42.22 percent. Meanwhile, the proportion of Chinese film and television works exported to $\mathrm{B} \& \mathrm{R}$ countries is also increasing year by year, exceeding $35 \%$ in 2018 , while the figure was less than $17 \%$ in 2010. It can be seen that the export of Chinese film and television works to B\&R countries is developing rapidly and has great potential.

However, it is worth noting that due to the cultural distance, different countries and nations have different acceptability to other countries' cultural products, and the phenomenon of "cultural discount" may be exerting more and more profound influence on the export trade of cultural products. This effect has been shown to exist in many current studies. Compared with manufactured products, cultural products are more affected by cultural barriers caused by cultural differences, because cultural products have dual attributes of economy and culture, especially film and television products. Therefore, it is particularly important to explore the relationship between the cultural distance between countries and the export of film and television works. 
In the 1970s, the scholar Greet Hofstede [1] first proposed and defined the concept of cultural distance as the difference in thinking mode between different groups due to cultural differences. The dimensions of cultural differences in different countries or regions mainly include six dimensions: power distance, individualism/collectivism, masculinity/femininity, uncertainty avoidance, long-term/short-term orientation, indulgence/restraint. Over time, there have been many different ways of measuring cultural differences or cultural distance. These methods were widely used in later studies, and the theory of cultural distance was applied to different areas of human life. For example, the explanatory power of cultural distance on transnational happiness differences [2], population self-rated health [3], enterprise internationalization [4], bilateral trade [5] and other fields has been confirmed in the studies of scholars around the world. However, some scholars have questioned the explanatory power of cultural distance. Harzing et al. [6] found through literature review and enterprise survey that once the background of home country and host country is taken into account, the explanatory power of cultural distance on the choice of international business model is very limited, and any significant influence may only be caused by insufficient sampling.

Focusing on the field of cultural trade that we pay attention to, scholars around the world have made rich research conclusions and achievements on the relationship between cultural distance and cultural trade. Many studies have found that cultural distance or cultural discount will inhibit the export of cultural products. For example, White et al. [7] studied the export of cultural products in American states and found that cultural distance inhibited the national-level export of cultural products. Ferreira et al. [8] studied the music market and found that local bias and language distance had a negative impact on the trade volume of music products through the gravity model. Trade in cultural services will be affected as well as cultural products. Harms et al. [9] studied the effects of cultural factors on international service trade and found that cultural distance has a negative effect on overall service trade. Meanwhile, different types of services may have different sensitivity to cultural distance. Azar et al. [10] used structural equation model to verify the relationship between cultural distance, innovation strategy and export performance, and found that cultural distance can promote managers' innovation decisions and thus improve enterprises' export performance.

At present, more and more scholars begin to pay attention to the influence of cultural distance on the trade of film and television works. Hanson et al. [11] found that language similarity had a strong influence on the export of American films. Some scholars have found a significant U-shaped relationship between cultural distance and film export. For example, Moon et al. [12] found a U-shaped relationship between cultural distance between countries and film product sales through the data analysis of the international retail of American films. Jane's [13] research also supports the view that cultural distance has a U-shaped impact on global cultural products. In addition, the results of Georgios et al. [14] show that the success of cultural distance in the domestic market and the size of film budget will affect the film trade between countries. Choi et al. [15] studied the influence of trade barriers and cultural distance on the domestic film market share in the US, and they concluded that cultural distance and market size were important factors affecting the domestic market share.

Based on existing literature, it can be seen that the relationship between cultural distance and the export of cultural products is still uncertain, but the former does have an impact on the latter. For different countries and product categories, further research is needed to determine the specific correlation. At the same time, there is a lack of research on $B \& R$ countries. In this paper, $B \& R$ countries are selected as samples to prove the effect of cultural distance on film and television works through some evidence, and further explore how cultural distance affects the export of film and television works, which is innovative.

The rest of the paper is structured as follows: Section 2 introduces the data and theoretical models. The third section gives the empirical results and carries on the robustness test; the fourth section summarizes this paper.

\section{ANALYTICAL FRAMEWORK}

\subsection{Theoretical basis and research hypothesis}

Transaction cost theory and demand similarity theory are the basis of this paper. Information asymmetry is prevalent in economic activities. In order to gain a more advantageous negotiating position, both sides of trade are bound to seek to master more information about traders and products. However, the existence of cultural distance hinders this process, which increases the cost of language communication, behavioral understanding and the discovery of the value of film and television works. Similarly, cultural distance also hinders the negotiation in the process of trade and the distribution and feedback of post-trade film and television works. Therefore, the existence of cultural distance may affect the export of film and television works by increasing transaction costs.

In the export of Chinese film and television works, the closer the per capita income level of the importing country is to that of China, the more similar the two countries' demand for film and television works is. Film and television works are cultural products with high added value, whose production and dissemination depend on the audience's understanding and preference for film content. The existence of cultural distance means that the demand structure of film and television works in 
two countries must be different. The larger the cultural distance is, the smaller the similarity of demand is, and the greater the obstacle to the export of film and television works is. The smaller the cultural distance, the more overlapping demands, the more conducive to the export of film and television works.

To sum up, this paper holds that: under the background of B\&R initiative, cultural distance has a significant inhibiting effect on the export of Chinese film and television works.

\subsection{Variable Design}

Total export of film and television works (EX) is the explained variable. The natural logarithm of China's total export of film and television works to B\&R countries is used to measure the degree of export trade of film and television works.

Cultural distance (CulDist) is the core explanation variable, which represents the cultural differences between China and the sample countries. Refer to the calculation methods of Kogut et al. [16] and Qi et al. [17] , we synthesized the scores of Hofstede's six dimensions of cultural distance, namely, power distance(PDI), individualism/collectivism

(IDV), masculinity/femininity (MAS), uncertainty avoidance (UAI), long-term/short-term orientation (LTO), indulgence/restraint (IND). To construct the improved KSI index of cultural distance between China and B\&R countries, the calculation method is as follows:

$$
\text { CulDist }_{i, c}=\sum_{j=1}^{6}\left[\left(C u l_{i, j}-C u l_{c, j}\right)^{2} / V_{j}\right] / 6+1 / T_{i, c}
$$

In Formula (1), $C u l_{i, j}$ and $C u l_{c, j}$ represent the score of the $i$ th country and China in the $j$ th dimension respectively; and $V_{j}$ represents the variance of the score of the $j$ th dimension between China and $B \& R$ countries. In order to better reflect the dynamic change of cultural distance between countries; $1 / T_{i, c}$ is introduced as the reciprocal term of the years of diplomatic relations between China and B\&R countries. It shows that with the longer time of diplomatic relations between the two countries, the cultural integration between countries is gradually enhanced and the cultural distance is gradually reduced.

In addition to cultural distance, there are many influencing factors that will affect the export of Chinese film and television works. To make the model more realistic, we selects the per capita GDP, population, number of Confucius institute, bilateral trade volume, the host country level of film and TV exports, human development, infrastructure, government efficiency variable as control variables. Variable names and definitions are shown in Table 1.

Table 1 Variable definitions

\begin{tabular}{|c|l|}
\hline Variable & \multicolumn{1}{|c|}{ Definition and Value } \\
\hline EX & $\begin{array}{l}\text { The natural logarithm of the export volume } \\
\text { of film and television works between China } \\
\text { and B\&R countries }\end{array}$ \\
\hline CuIDist & $\begin{array}{l}\text { KSI index of Cultural Distance between } \\
\text { China and B\&R countries }\end{array}$ \\
\hline PCGDP & The natural logarithm of GDP per capita \\
\hline POP & The natural log of the total population \\
\hline CSP & $\begin{array}{l}\text { The natural logarithm of the number of } \\
\text { Confucius Institutes }\end{array}$ \\
\hline TRADE & $\begin{array}{l}\text { The natural logarithm of total bilateral } \\
\text { imports and exports }\end{array}$ \\
\hline TEX & $\begin{array}{l}\text { The natural logarithm of the host country's } \\
\text { film and television exports }\end{array}$ \\
\hline HDI & Human development index \\
\hline INF & $\begin{array}{l}\text { Natural logarithm of the number of secure } \\
\text { servers per million people }\end{array}$ \\
\hline GE & The efficiency of government governance \\
\hline YEAR & Annual dummy variable \\
\hline
\end{tabular}

\subsection{Sample selection and data sources}

Annual data of China and B\&R countries from 2010 to 2018 were used as samples. After processing the missing values of the original data, we screen out the data of 54 sample countries for 9 years, a total of 486 observed values, and the data structure is strongly balanced panel data.

The original score data of the six dimensions of cultural distance came from the official website of Hofstede, and the data of the years of diplomatic relations used in the KSI index came from the official website of the Ministry of Foreign Affairs of China. Total export of film and television works, bilateral trade volume between China and B\&R Countries and film and television exports of the host country are all from the UN Comtrade Database, and adjusted according to 2010 constant dollars. Among other control variables, per capita GDP, total population and infrastructure data of each country are all from the World Bank database (WDI), and economic indicators are calculated in 2010 constant dollars. The number of Confucius Institutes is from the Annual Confucius Institute Report, which is downloaded from CSMAR. The Human Development Index is derived from the Human Development Report published by the United Nations Development Programme (UNDP). The government efficiency data comes from the Global Governance Indicators Dataset (WGI). 


\subsection{Model setting}

According to the existing panel data structure, we use panel fixed effect model for regression analysis. Specific regression models for core explanatory variables and control variables are constructed as follows:

$$
\begin{aligned}
& E X_{\mathrm{i}, \mathrm{t}}=\beta_{0}+\beta_{1} \text { Culdist }_{\mathrm{i}, \mathrm{t}}+\varepsilon_{\mathrm{i}, \mathrm{t}} \\
E X_{\mathrm{i}, \mathrm{t}}= & \beta_{0}+\beta_{1} P C G D P_{\mathrm{i}, \mathrm{t}}+\beta_{2} P O P_{\mathrm{i}, \mathrm{t}} \\
& +\beta_{3} C S P_{\mathrm{i}, \mathrm{t}}+\beta_{4} T R A D E_{\mathrm{i}, \mathrm{t}}+\beta_{5} \mathrm{TEX}_{\mathrm{i}, \mathrm{t}} \\
& +\beta_{6} H D I_{\mathrm{i}, \mathrm{t}}+\beta_{7} I N F_{\mathrm{i}, \mathrm{t}}+\beta_{8} G E_{\mathrm{i}, \mathrm{t}}+\varepsilon_{\mathrm{i}, \mathrm{t}}
\end{aligned}
$$

Cultural distance and other control variables were incorporated into the model at the same time, and the modified model was:

$$
\begin{aligned}
E X_{\mathrm{i}, \mathrm{t}} & =\beta_{0}+\beta_{1} \text { CulDist }_{\mathrm{i}, \mathrm{t}}+\beta_{2} P C G D P_{\mathrm{i}, \mathrm{t}}+\beta_{3} P O P_{\mathrm{i}, \mathrm{t}} \\
& +\beta_{4} C S P_{\mathrm{i}, \mathrm{t}}+\beta_{5} T R A D E_{\mathrm{i}, \mathrm{t}}+\beta_{6} \mathrm{TEX}_{\mathrm{i}, \mathrm{t}}+\beta_{7} H D I_{\mathrm{i}, \mathrm{t}} \\
& +\beta_{8} I N F_{\mathrm{i}, \mathrm{t}}+\beta_{9} G E_{\mathrm{i}, \mathrm{t}}+\varepsilon_{\mathrm{i}, \mathrm{t}}
\end{aligned}
$$

In Equations (2), (3) and (4), $i$ represents the $i$ th country, $\mathrm{t}$ represents the $\mathrm{t}$ year, $\beta_{1} \sim \beta_{9}$ represents the regression coefficients and $\varepsilon_{\mathrm{i}, \mathrm{t}}$ represents the random error term.

\section{RESULTS AND DISCUSSION}

\subsection{Regression analysis}

STATA16.0 software was used for measurement, and regression calculation was performed on Equations (2), (3) and (4) respectively, corresponding to the results in columns (1), (2) and (3) in Table 2.

Columns (1), said in the film and television works (EX) as dependent variable, the total export to cultural distance (CulDist) as the independent variable, control variable is not set up, the culture of film and television works exports in relation to the distance was not significant. This may be caused by a lack of omitted variables, sample size or causes such as the relationship is not obvious, the results still need further according to the control variables are considered.

After adding control variables to column (1), column (3) is obtained. It is found that the cultural distance of the core explanatory variable changes from insignificant to significant at the level of $5 \%$, showing a negative correlation with the regression coefficient of -12.162 , indicating that cultural distance has a significant inhibitory effect on the total export of film and television works. This result preliminarily supports our research hypothesis.
Table 2 Regression results of the influence of cultural distance on the export of film and television works

\begin{tabular}{|c|c|c|c|c|}
\hline & $(1)$ & $(2)$ & $(3)$ & $(4)$ \\
\hline Variable & EX & EX & EX & EX \\
\hline CulDist & 6.665 & & 12.162 & $0.481 * *$ \\
\hline & $(1.32)$ & & $(2.29)$ & $(2.05)$ \\
\hline PCGDP & & 1.077 & 1.354 & $0.474 *$ \\
\hline & & $(0.96)$ & $(1.21)$ & $(1.85)$ \\
\hline POP & & 0.764 & 0.995 & $1.179 * *$ \\
\hline & & $(0.44)$ & $(0.58)$ & $(8.61)$ \\
\hline CSP & & 0.088 & 0.021 & 0.013 \\
\hline & & $(0.38)$ & $(0.09)$ & $(0.10)$ \\
\hline TRADE & & 0.361 & $0.516 *$ & $0.465 * *$ \\
\hline & & $(1.42)$ & $(1.97)$ & $(3.56)$ \\
\hline TEX & & 0.057 & 0.057 & 0.065 \\
\hline & & $(1.15)$ & $(1.16)$ & $(1.56)$ \\
\hline HDI & & 3.140 & 3.007 & 2.32 \\
\hline & & $(0.30)$ & $(0.29)$ & $(0.99)$ \\
\hline INF & & $0.264 *$ & $0.295 *$ & $0.189 * *$ \\
\hline & & $(2.89)$ & $(3.21)$ & $(2.23)$ \\
\hline GE & & 0.319 & 0.381 & $0.627 * *$ \\
\hline & & $(0.68)$ & $(0.82)$ & $(2.6)$ \\
\hline Constant & 31.88 & 0.252 & 29.511 & $22.779 *$ \\
\hline & $(2.23)$ & $(0.01)$ & $(0.94)$ & $(11.51)$ \\
\hline Individual & contr & control & control & control \\
\hline Time & contr & control & control & control \\
\hline Observatio & 486 & 486 & 486 & 486 \\
\hline$R^{2}$ & 0.029 & 0.052 & 0.064 & 0.729 \\
\hline
\end{tabular}

Note: $* * * \mathrm{P}<0.01, * * \mathrm{P}<0.05, * \mathrm{P}<0.1$; the $\mathrm{T}$ values are in parentheses.

\subsection{Endogenous treatment}

The above results show that cultural distance does have a significant impact on the export of Chinese film and television works. But it is worth noting that, as spiritual and cultural products, the export of film and television works will also have an impact on the cultural distance between the two countries: intuitively, the greater the export of film and television works, the smaller the cultural distance is likely to be. In order to solve the endogeneity problems caused by reverse causality and omitted variables, this paper adopts instrumental variable method to deal with the endogeneity of the model. 


\subsubsection{Selecting Tool variables}

Referring to the study of Spolare et al. [18], this paper constructed genetic distance (GEN) as the instrumental variable of cultural distance (CulDist). Spolare et al. believed that genes were an appropriate variable to depict cultural differences, and genetic distance could represent differences in beliefs, conventions, habits, prejudices and other cultural characteristics.

To further investigate the rationality of the selection of instrumental variables, we conducted a weak instrumental variable test for genetic distance, and the results are shown in Table 3. It can be seen from the table that the three statistical values are all greater than the empirical value or critical value, which rejects the null hypothesis of weak instrumental variables, indicating that the genetic distance of instrumental variables is strongly correlated with the cultural distance of endogenous variables and can be used as instrumental variables.

Table 3 Test results of weak instrumental variables

\begin{tabular}{|c|c|c|}
\hline Statistic & $\begin{array}{c}\text { Test } \\
\text { value }\end{array}$ & $\begin{array}{c}\text { P } \\
\text { value } \\
\text { s }\end{array}$ \\
\hline $\begin{array}{c}\text { Sanderson-Windmeijer } \\
\text { multivariate F test }\end{array}$ & 42.85 & 0.000 \\
\hline $\begin{array}{c}\text { Cragg-Donald Wald F } \\
\text { statistic }\end{array}$ & 42.85 & - \\
\hline $\begin{array}{c}\text { Kleibergen-Paap rk LM } \\
\text { statistic }\end{array}$ & 40.76 & 0.000 \\
\hline
\end{tabular}

\subsubsection{Endogeneity test}

Referring to the practice of Spolare et al. [18], this paper adopts the proportion of China's international immigrant population in the sample country as an indicator to measure genetic distance. The results of endogeneity test of the model with genetic distance as the instrumental variable of cultural distance are shown in Column (4) of Table 2.

The results of endogeneity test in Table 2 and their causes are analyzed as follows:

First of all, after considering the endogenous influence, cultural distance still has a negative impact on the export of Chinese film and television works. Cultural distance and the total export of film and television works are significant at the level of $5 \%$, and the regression coefficient changes from -12.162 to $\quad-0.481$. This means that the greater the cultural distance between China and B\&R countries, the smaller the total export of Chinese film and television works to the country. Cultural distance inhibits the export of film and television works, which is consistent with the expectation. The results show that the existence of cultural distance will materialize and reflect on Chinese film and television works, resulting in the increase of transaction costs of both sides of the trade, thus hinders the export of Chinese film and television works. At the same time, as spiritual and cultural products, the more similar the demand structure of film and television works is to those countries with similar Chinese cultural background, so it is easier to realize the trade with Chinese film and television works. Therefore, the hypothesis of this paper that cultural distance plays a negative inhibiting role in the export of Chinese film and television works to $B \& R$ countries has been basically verified. This result is similar to the conclusion of many literatures on the relationship between cultural distance and trade of cultural products.

Secondly, after joining instrumental variable, goodness of fit of the model value $(72.9 \%)$ significantly increased, from the point of view of control variables, part of the control variable is significant and has the obvious improvement: per capita GDP, population, bilateral trade volume, infrastructure and government efficiency variable are proved under different level has correlation with the total value of the export of Chinese film and television works.

\subsection{Robustness test}

In order to further test the accuracy and reliability of regression results, the robustness test was carried out by replacing explanatory variables and dividing specific cultural dimensions.

\subsubsection{Replacing explanatory Variables}

Different calculation methods for cultural distance may lead to different results. Based on Hofstede's dimension of cultural distance, in addition to KSI index, another commonly used index is Euclidean Index (EDI), which measures cultural distance through Euclidean spatial distance measurement method. The difference between EDI index and KSI index lies in that EDI index proposes that different cultural dimensions have different influences on cultural distance. The calculation method is as follows:

$$
\text { CulDist }_{i, c}^{2}=\sqrt{\sum_{j=1}^{6}\left[\left(\mathrm{Cul}_{i, j}-\mathrm{Cul}_{c, j}\right)^{2} / V_{j}\right]}+1 / T_{i, c}(5)
$$

The definition of symbols in Formula (5) is the same as that in Formula (1).The regression results of each variable and total export of film and television works are shown in Column (1) in Table 4.

\subsubsection{Partial dimensional regression}

The cultural distance index is decomposed and the influence of distance from different cultural dimensions on the export of film and television works between China 
and B\&R countries is tested. The results are shown in Columns (2) - (7) in Table 4.

Table 4 Robustness test

\begin{tabular}{|c|c|c|c|c|c|c|c|}
\hline & (1) & (2) & (3) & (4) & (5) & (6) & (7) \\
\hline Variable & \multicolumn{7}{|c|}{ EX } \\
\hline \multirow{2}{*}{ CulDist $^{2}$} & $0.535^{\star *}$ & & & & & & \\
\hline & (2.08) & & & & & & \\
\hline \multirow[t]{2}{*}{ PDI } & & $0.488^{*}$ & & & & & \\
\hline & & $(1.86)$ & & & & & \\
\hline \multirow[t]{2}{*}{ IDV } & & & 0.618 & & & & \\
\hline & & & (1.64) & & & & \\
\hline \multirow[t]{2}{*}{ MAS } & & & & $0.324^{\star \star}$ & & & \\
\hline & & & & (2.03) & & & \\
\hline \multirow[t]{2}{*}{ UAI } & & & & & $0.326^{*}$ & & \\
\hline & & & & & $(1.90)$ & & \\
\hline \multirow[t]{2}{*}{ LTO } & & & & & & 0.444 & \\
\hline & & & & & & (1.43) & \\
\hline \multirow[t]{2}{*}{ IND } & & & & & & & 2.492 \\
\hline & & & & & & & $(0.56)$ \\
\hline \multirow[t]{2}{*}{ PCGDP } & $0.477^{\star}$ & 0.441 & 0.484 & 0.498 & 0.191 & 1.683 & 3.588 \\
\hline & $(1.88)$ & (1.63) & $(1.5)$ & (1.33) & $(0.89)$ & $(1.51)$ & $(0.58)$ \\
\hline \multirow[t]{2}{*}{ POP } & $1.176^{\star \star *}$ & $1.282^{* * *}$ & $0.971^{* * *}$ & $0.903^{* * *}$ & $1.509^{* * *}$ & $1.236^{\star * *}$ & 0.842 \\
\hline & $(8.75)$ & $(6.97)$ & $(6.2)$ & $(6.46)$ & $(5.46)$ & $(5.66)$ & (1.48) \\
\hline \multirow[t]{2}{*}{ CSP } & 0.053 & 0.055 & 0.472 & 0.092 & 0.093 & $0.340^{*}$ & 0.751 \\
\hline & $(0.42)$ & $(0.31)$ & (1.12) & $(0.78)$ & $(0.73)$ & (1.77) & $(0.44)$ \\
\hline \multirow[t]{2}{*}{ TRADE } & $0.478^{\star \star \star}$ & $0.343^{*}$ & $0.474^{\star \star *}$ & $0.626^{\star * *}$ & 0.25 & $0.637^{\star \star \star}$ & 0.457 \\
\hline & (3.83) & (1.75) & $(2.97)$ & $(6.7)$ & $(1.06)$ & $(4.84)$ & $(0.93)$ \\
\hline \multirow[t]{2}{*}{ TEX } & $0.081^{\star *}$ & 0.042 & $0.089^{\star *}$ & $0.118^{\star \star \star}$ & $0.125^{\star \star \star}$ & 0.012 & 0.455 \\
\hline & $(2.23)$ & $(0.75)$ & $(2.05)$ & (3.93) & $(3.93)$ & $(0.13)$ & $(0.43)$ \\
\hline \multirow[t]{2}{*}{ HDI } & 2.61 & 2.623 & 3.552 & $8.608^{\star \star \star}$ & $12.600^{\star \star \star}$ & 10.551 & 59.952 \\
\hline & $(1.16)$ & $(1.04)$ & (1.32) & $(2.94)$ & $(2.61)$ & $(0.96)$ & $(0.52)$ \\
\hline \multirow[t]{2}{*}{ INF } & $0.176^{\star \star}$ & $0.152^{*}$ & $0.341^{* *}$ & $0.192^{\star *}$ & $0.216^{\star *}$ & 0.028 & 0.725 \\
\hline & $(2.16)$ & $(1.74)$ & $(2.05)$ & $(2.23)$ & $(2.21)$ & $(0.18)$ & (0.65) \\
\hline \multirow[t]{2}{*}{ GE } & $0.521^{\star *}$ & $1.391^{\star *}$ & 0.275 & $0.561^{\star * *}$ & 0.156 & $0.569^{*}$ & 4.901 \\
\hline & $(2.46)$ & $(2.3)$ & $(1.11)$ & $(2.48)$ & $(0.47)$ & $(1.76)$ & $(0.6)$ \\
\hline \multirow[t]{2}{*}{ Constant term } & $22.581^{\star * *}$ & $22.071^{* * *}$ & $22.021^{\star * *}$ & $19.098^{\star * *}$ & $28.963^{\star \star \star}$ & $26.350^{\star \star *}$ & 8.165 \\
\hline & $(11.22)$ & $(9.07)$ & $(7.91)$ & $(5.57)$ & $(11.33)$ & $(11.20)$ & 0.14 \\
\hline Individual effect & control & control & control & control & control & control & control \\
\hline Time effect & control & control & control & control & control & control & control \\
\hline Observations & 486 & 486 & 486 & 486 & 486 & 486 & 486 \\
\hline 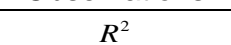 & 0.736 & 0.671 & 0.576 & 0.723 & 0.685 & 0.441 & 2.661 \\
\hline
\end{tabular}

Note: $* * * \mathrm{P}<0.01, * * \mathrm{P}<0.05, * \mathrm{P}<0.1$; the $\mathrm{T}$ values are in parentheses.

As can be seen from column (1) in Table 4, EDI index is significantly negatively correlated with the total export of Chinese film and television works at the level of 5\%. The correlation coefficient is -0.535 , which is very close to KSI index (-0.481), indicating that the model results are basically consistent after the replacement of explanatory variables. The model results are robust.

The fractal dimension regression results in Table 4 show that: column (2) power distance, column (4) masculinity/femininity, and column (5) uncertainty avoidance have a significant negative impact on the export of Chinese film and television works, which also proves the robustness of the research model. Further analysis found that:
(1) Power distance actually reflects the distribution of power in an organization or society. With the significant difference in the degree of power distance, the management of the film and television market in some countries and the restrictions of laws and regulations are also far from China, which will cause greater obstacles to negotiations and exchanges in the process of export trade with Chinese film and television works. It will increase the transaction costs of trading companies and is not conducive to the export of Chinese film and television works.

(2) Masculinity/feminization reflects the decisionmaking attitude and tendency of the masculine culture and the subject of the feminine culture towards trade competition and cooperation. Countries with a more masculine culture are more aggressive, purposeful and 
competitive, and are less willing to pursue cooperation in the film and television trade. While countries with feminine culture advocate win-win cooperation, they are more likely to compromise in negotiations to seek cooperation. Countries that have a large gap with China in this dimension also have more differences in the film and television trade negotiations, which leads to a hindrance to the film and television export trade.

(3) Uncertainty avoidance reflects the attitude and response mode of enterprises and people in various countries to future uncertainty. The significant gap in this dimension will lead to uncertain expectations in the film and television trade and changes in trust between countries, resulting in increased transaction costs or different demand structures, and hindering the export of Chinese film and television works.

\section{CONCLUSION}

In the conclusion of many previous studies, whether cultural distance has an impact on product trade and the direction of influence has not been determined. However, according to the research of this paper, as far as China is concerned, cultural distance does have a restraining effect on the export of the country's film and television works. The significant differences between Chinese culture and the diversified cultures of B\&R countries lead to the existence of cultural distance, which increases the cost of Chinese film and television works export, and ultimately leads to the negative impact of cultural distance on Chinese film and television works export. In addition, the results of sub-dimension regression prove that power distance, masculinity/femininity and uncertainty avoidance play a particularly prominent inhibiting role, so these three dimensions are also the key factors and starting points for China to improve the export of film and television works by reducing trade barriers. In a word, China should treat the influence of cultural distance correctly, make good use of it, avoid risks and constantly promote the export of film and television works.

\section{REFERENCES}

[1] Hofstede, G. (2011). Dimensionalizing Cultures: The Hofstede Model in Context. Online Readings in Psychology and Culture, 2(1).

[2] Ye, D., Ng, Y. K., \& Lian, Y. (2015). Culture and Happiness. Soc Indic Res, 123(2), 519-547.

[3] Detollenaere, J., Baert, S., \& Willems, S. (2018). Association between cultural distance and migrant self-rated health. Eur J Health Econ, 19(2), 257-266.

[4] Beugelsdijk, S., Kostova, T., Kunst, V. E., Spadafora, E., \& van Essen, M. (2018). Cultural Distance and Firm Internationalization: A Meta-
Analytical Review and Theoretical Implications. J Manage, 44(1), 89-130.

[5] Cyrus, T. L. (2015). Culture and Trade in the European Union. Journal of Economic Integration, 30(2), 206-239.

[6] Harzing, A.-W., \& Pudelko, M. (2015). Do We Need to Distance Ourselves from the Distance Concept? Why Home and Host Country Context Might Matter More Than (Cultural) Distance. Management International Review, 56(1), 1-34.

[7] White, R. , \& Tadesse, B. . (2009). Immigrants, cultural distance and u.s. state-level exports of cultural products. North American Journal of Economics \& Finance, 19(3), 331-348.

[8] Ferreira, F., \& Waldfogel, J. (2013). Pop Internationalism: Has Half a Century of World Music Trade Displaced Local Culture? The Economic Journal, 123(569), 634-664.

[9] Harms, P., \& Shuvalova, D. (2020). Cultural distance and international trade in services: A disaggregate view. Economic Systems, 44(2).

[10]Azar, G., \& Drogendijk, R. (2016). Cultural distance, innovation and export performance. European Business Review, 28(2), 176-207.

[11] Hanson, G., \& Xiang, C. (2011). Trade barriers and trade flows with product heterogeneity: An application to US motion picture exports. Journal of International Economics, 83(1), 14-26.

[12] Moon, S., \& Song, R. (2015). The Roles of Cultural Elements in International Retailing of Cultural Products: An Application to the Motion Picture Industry. Journal of Retailing, 91(1), 154-170.

[13] Jane, W.-J. (2021). Cultural distance in international films: An empirical investigation of a sample selection model. Journal of Economics and Business, 113.

[14] Alaveras, G., Gomez-Herrera, E., \& Martens, B. (2018). Cross-border circulation of films and cultural diversity in the EU. Journal of Cultural Economics, 42(4), 645-676.

[15] Choi, Y.-J., Min, C.-k., \& Park, C. (2019). Effects of Trade Barriers and Cultural Distance on the Domestic Market Share in the Film Industry. World Trade Review, 19(1), 61-74.

[16] Kogut B , Nath R .(1998). The Effect of National Culture on the Choice of Entry Mode. Journal of International Business Studies, 19(3):411-432.

[17] Jianhong Q, \& Li Y. (2012). The locational determinants of China's OFDI are based on the tests 
of geographical distance and cultural distance., 4046.

[18] Spolaore E, Wacziarg R. (2013). War and Relatedness[C]// Competitive Advantage in the Global Economy (CAGE). Competitive Advantage in the Global Economy (CAGE). 